\title{
The role of bariatric surgery in the treatment of type 2 diabetes mellitus
}

\author{
${ }^{1}$ WB Leong, ${ }^{2 S}$ Taheri \\ ${ }^{1}$ Clinical Research Fellow, Weight Management Services, Heart of England NHS Foundation Trust; ${ }^{2}$ Senior Lecturer in Diabetes and \\ Consultant Endocrinologist, School of Clinical and Experimental Medicine, University of Birmingham and Weight Management Services, \\ Heart of England NHS Foundation Trust, Birmingham, UK
}

ABSTRACT Medical treatments for patients with type 2 diabetes mellitus and class II and above obesity (body mass index greater than $35 \mathrm{~kg} / \mathrm{m}^{2}$ ) are currently limited to treatment of diabetes and prevention of its vascular complications. Bariatric surgery is by far the most effective treatment not only for weight loss, but also for improvement or remission of diabetes. This editorial examines the current evidence for the impact of bariatric surgery on weight loss and type 2 diabetes.

KEYWORDS Type 2 diabetes mellitus, bariatric surgery, diabetes remission, obesity

DECLARATION OF INTERESTS This work was funded by the National Institute for Health Research (NIHR) through the Collaborations for Leadership in Applied Health Research and Care for Birmingham and Black Country (CLAHRC-BBC) programme. Dr Leong is funded through an unrestricted educational grant from Allergan. Dr Taheri has received educational funding support from Lilly UK and research support from Novo Nordisk, Allergan, Philips Respironics and Resmed.
Correspondence to S Taheri, NIHR CLAHRC Theme 8, School of Health \& Population Sciences, The University of Birmingham, Room 109, Public Health Building, Edgbaston, Birmingham B I5 2TT, UK

tel. +44 (0) 121 4243339

e-mail staheri@me.com

\section{INTRODUCTION}

Type 2 diabetes mellitus (T2D) is a significant healthcare challenge driven by the increasing prevalence of obesity.1,2 There are currently at least 2.6 million people with diabetes in the UK and the figure is predicted to rise to more than five million by $2025 .^{3}$ Weight reduction in patients with T2D improves glycaemia and other cardiometabolic abnormalities and in some cases can result in diabetes remission. ${ }^{4,5}$ Lifestyle interventions, with or without the addition of weight loss medications, usually lead to modest weight loss, which is frequently not maintained. ${ }^{4.6}$ Currently, bariatric surgery is the most effective treatment for individuals with obesity complicated by T2D. Most procedures are generally performed laparoscopically as observed in the Longitudinal Assessment of Bariatric Surgery (LABS) study. ${ }^{7}$ Bariatric surgery is not only effective in weight reduction, it also results in greater improvement and remission of T2D. The most common procedures carried out in the National Health Service (NHS) are laparoscopic adjustable gastric banding (LAGB), laparoscopic Roux-en-Y gastric bypass (RYGB) and laparoscopic sleeve gastrectomy (LSG).

The International Diabetes Federation (IDF) has recommended bariatric surgery as a treatment option for individuals with T2D and a body mass index (BMI) of $35 \mathrm{~kg} / \mathrm{m}^{2}$ or more, ${ }^{8}$ consistent with the Scottish Intercollegiate Guidelines Network (SIGN) and the National Institute for Health and Clinical Excellence (NICE) guidelines. ${ }^{910}$ The BMI threshold is different compared to individuals without co-morbidities (BMI $\geq 40 \mathrm{~kg} / \mathrm{m}^{2}$ ) because bariatric surgery is likely to result in significant improvement in T2D at a lower BMI.

Improvement and remission of T2D after bariatric surgery are likely to be due to a combination of weight reduction mediated through alterations in appetite hormones and alterations in hormones regulating glycaemic control. Appetite hormones are hormones released (mainly by the gut) to alter food intake and energy expenditure. They act either directly or indirectly on the hypothalamus, a key centre for homeostatic regulation. Ghrelin is an example of an appetite stimulating hormone" while peptide tyrosine-tyrosine (PYY) suppresses appetite. ${ }^{12}$ Bariatric surgery, especially RYGB, also results in greater improvement in insulin sensitivity. Adiponectin, an adipocytokine hormone, could be a potential mediator. Levels are low in obesity and T2D. ${ }^{13,14}$ Sustained weight reduction after bariatric surgery can lead to reversal of the levels and thus improvement in insulin resistance state. ${ }^{15}$

\section{REMISSION OF DIABETES AFTER BARIATRIC SURGERY}

Remission or cure?

Glycaemic control improves significantly after bariatric surgery in T2D and glycaemia may return to a prediabetes level. However, these individuals are still at risk of glycaemic deterioration in the future and may become 
diabetic again. This is supported by the Swedish Obese Subjects (SOS) study in which T2D remission rate was $36 \%$ at 10 years compared to $72 \%$ at two years followup. ${ }^{16}$ Moreover, T2D individuals who have achieved a pre-diabetes state (impaired fasting glucose [IFT] or impaired glucose tolerance [IGT] states) after bariatric surgery still have an increased risk in all-cause mortality as well as cardiovascular disease in the near future. ${ }^{17}$ Also, there is a paucity in the long-term data on microvascular complications after bariatric surgery in this group of individuals. Due to these reasons, the more appropriate medical terminology is remission of diabetes although the terminology 'cure' has also been used in the literature.

\section{Definitions}

There is no general consensus on the definition of diabetes remission. Because of this, the American Diabetes Association (ADA) released a consensus statement on the definition of diabetes remission in 2009. The statement suggested that remission can be partial, complete or prolonged depending on the duration of normality in glycaemic control without the need for anti-diabetic medications or procedures. ${ }^{18}$ Partial remission was defined as a fasting plasma glucose level of $<7.0$ millimoles per litre $(\mathrm{mmol} / \mathrm{L})$ or $\mathrm{HbAlc}$ $<48$ millimoles per mole $(\mathrm{mmol} / \mathrm{mol})(6.5 \%)$ for at least 12 months without the help of medications or procedures. Complete remission was defined as a fasting plasma glucose level of $<5.6 \mathrm{mmol} / \mathrm{L}$ or glycated haemoglobin (HbAlc) $<42 \mathrm{mmol} / \mathrm{mol}(6.0 \%)$ for at least 12 months, while prolonged remission was defined as complete remission achieved for at least five years without the need for medication or surgery. An HbAlc of $42 \mathrm{mmol} / \mathrm{mol}(6.0 \%)$ is still abnormal, representing impaired glucose tolerance (or pre-diabetes state). This $\mathrm{HbAlc}$ level, however, has a lower risk of diabetes microvascular complications used to define cut-off points for diabetes diagnosis.

Prior to the ADA statement, Buchwald et al. published two meta-analyses on T2D remission after bariatric surgery. Due to the absence of a universal definition at the time of publication, the authors formulated their own. They defined T2D remission as a fasting plasma glucose level of $<5.7 \mathrm{mmol} / \mathrm{L}$ or $\mathrm{HbAlc}<43 \mathrm{mmol} / \mathrm{mol}$ (6.1\%) without the help of hypoglycaemic medications. ${ }^{19,20}$ Currently there is no general international consensus on the definition of diabetes remission, so there is great diversity in reports of diabetes remission after bariatric surgery. However, the ADA consensus statement's definition is now beginning to gain increasing popularity in the literature.
Results from systematic review, meta-analyses and pooled data

In 2009, a meta-analysis of 621 studies by Buchwald et al. was published in which 29 were randomised controlled trials (RCT) and only ten of these were considered class one evidence. Results from these ten studies were then published in two categories: diabetes remission achieved in two years or more than two years. At two years, the greatest remission was achieved following gastric bypass (about $81 \%$ ) compared to the gastric band (55\%). Results from more than two years showed a reduction in diabetes remission rate with the gastric bypass (70.9\%) and a higher rate with the gastric band (58.3\%). ${ }^{19}$ A further meta-analysis by Buchwald et al. in 2004 involved I 36 studies with 19,388 patients. Most of them were case series with only one RCT in the analysis. The greatest diabetes remission was reported after gastric bypass surgery (83.8\%) followed by gastroplasty (68.2\%) and finally the gastric band $(47.8 \%){ }^{20}$ Dixon et al. performed a review of diabetes remission after LAGB in a total of 35 studies with only one RCT. After approximately one year, a weighted average or $52.3 \%$ achieved diabetes remission. Remission was lower at 24 months or longer (37.6\%). ${ }^{21}$

\section{Recent randomised controlled trials}

There are limited published RCTs examining the effect of bariatric surgery on diabetes remission. The sample sizes for these RCTs are relatively small. Despite this, the results are statistically significant because of the high effectiveness of bariatric surgery in glycaemic change, at least in the short term.

Mingrone and colleagues recently compared diabetes remission rates between gastric bypass $(n=20)$, biliopancreatic diversion $(n=20)$ and medical therapy $(n=20)$ in an RCT. Remission was defined as a fasting glucose level of $<5.6 \mathrm{mmol} / \mathrm{L}$ and a HbAlc of $<48 \mathrm{mmol} /$ $\mathrm{mol}(6.5 \%)$ for at least one year without anti-diabetes medications. The greatest remission percentage occurred after biliopancreatic diversion (95\%) followed by gastric bypass $(75 \%)$ and medical therapy $(0 \%)$. This equates to a relative risk of 7.5 (95\% confidence interval [Cl]: 1.97 to 28.6I) in the gastric bypass group and 9.5 (95\% Cl: 2.54 to $35.5 \mathrm{I}$ ) in the biliopancreatic diversion group for diabetes remission. ${ }^{22}$

An RCT performed in Australia comparing intensive lifestyle intervention (ILI) $(n=30)$ to LAGB $(n=30)$ found that the remission rate (defined as $\mathrm{HbAlc}<44 \mathrm{mmol} /$ $\mathrm{mol}[6.2 \%]$ and a fasting glucose level of $<7.0 \mathrm{mmol} / \mathrm{L}$ ) after two years was $73 \%$ in LAGB compared to $13 \%$ in the ILI group. The mean difference in reduction in the glycated haemoglobin between LAGB (-I.8I\%) and ILI $(-0.38 \%)$ was $1.43 \%$ ( $95 \% \mathrm{Cl}: 2.10$ to 0.80$)$. Although the 
majority of the LAGB patients achieved weight reduction in this study, one patient did not. ${ }^{5}$ Both the RCTs above demonstrate the greater effect of bariatric surgery when compared to lifestyle intervention on glycaemic control. A recent Taiwanese study examined the impact of gastric bypass $(n=30)$ and sleeve gastrectomy $(n=30)$. Diabetes remission was defined as a fasting glucose level of $<7.0 \mathrm{mmol} / \mathrm{L}$ or glycated haemoglobin of less than 48 $\mathrm{mmol} / \mathrm{mol}(6.5 \%)$, without the use of medication. Greater remission was found in the gastric bypass group (93\%) compared to the gastric sleeve $(47 \%)$. The mean reduction in glycated haemoglobin in gastric bypass recipients $(4.2 \%)$ was also higher compared to gastric sleeve recipients $(3.0 \%)^{23}$

\section{Remission of type 2 diabetes based on ADA criteria}

Recently, Pournaras et al. compared their results using the ADA and Buchwald et al. definitions. They reported their results from three bariatric centres: one in Norway and two in the UK. A total of 209 patients were followed up for 23 months and it was found that overall, $34.4 \%$ achieved complete remission and $13.4 \%$ achieved partial remission based on the ADA guidelines. This is compared to $49.3 \%$ achieving complete remission based on the definition used by Buchwald and colleagues. Patients who underwent gastric bypass surgery had the highest success rate compared to LSG ( 1.6 to 3.12 times higher) and LAGB (2.2 to 5.8 times higher) in diabetes remission. ${ }^{24}$

\section{Type 2 diabetes remission in the long term}

Long-term remission of T2D was assessed by the Swedish Obese Subjects (SOS) study, a non-randomised prospective observational study. Remission of diabetes for SOS was defined as a fasting plasma glucose level of $<7.0 \mathrm{mmol} / \mathrm{L}$ or a fasting capillary glucose level of $<6.1$ $\mathrm{mmol} / \mathrm{L}$. Participants were followed up for ten years after bariatric surgery. The majority of the participants received either a gastroplasty or a gastric band (95\%).At two years, the diabetes remission rate was $72 \%$ and this decreased to $36 \%$ at ten years. ${ }^{16}$ This study suggests that diabetes remission may not be sustained in half of the patients over time and reinforces the importance of long-term follow-up, including assessments for complication in patients with diabetes who undergo bariatric surgery.

\section{BARIATRIC SURGERY AND CARDIO- METABOLIC RISK}

Management of T2D also includes blood pressure (BP) and lipid control as part of cardiovascular risk reduction. Apart from better glycaemic control, bariatric surgery also results in improvement in blood pressure control as well as lipid profile. A recent systematic review of 52 studies published from 1950 to 2010 consists of 16,867 patients. The mean follow-up period was 34 months. Results showed that after bariatric surgery, there was a 15 millimetres of mercury $(\mathrm{mm} \mathrm{Hg})$ drop in systolic BP. Resolution of hypertension and lipid profile was similar in LAGB (58\% and $60 \%$ respectively) and RYGB $(60 \%$ and $57 \%$ respectively) ${ }^{25}$ These results differed from Buchwald et al. as they reviewed studies published from 1990 to 2003 and reported a greater resolution in gastric bypass recipients $(75.4 \%)$ compared to LAGB $(38.4 \%)^{20}$

A systematic review on LSG examined 33 studies from 2000 to 201 I of which one study was an RCT. Resolution of hypertension was defined as discontinuation of any anti-hypertensive medications. There were a total of 3,997 patients. Resolution of hypertension occurred in $58 \%$ of patients after 12 months. ${ }^{26}$ In the SOS study, resolution of hypertension was defined as BP of less than $140 / 90 \mathrm{~mm} \mathrm{Hg}$. Thirty-four per cent of patients achieved resolution of hypertension at two years but this was reduced to $19 \%$ at ten years. ${ }^{16}$

A systematic review performed by Buchwald and colleagues demonstrated that weight loss surgery resulted in improvements in lipids profile. Improvements of hyperlipidaemia, hypercholesterolaemia and hypertriglyceridaemia were greater after RYGB $(96.9 \%, 94.9 \%$ and $91.2 \%$ respectively) compared to LAGB (58.9\%, $78.0 \%$ and $77 \%$ respectively). ${ }^{20}$ Other studies have shown between $18 \%$ and $38 \%$ reduction in triglycerides level, and between $13 \%$ and $30 \%$ improvements in highdensity lipoprotein (HDL)-cholesterol level|,22,27,28 after bariatric surgery. Significant changes are not seen in LDL-cholesterol level after surgery ${ }^{5,27,28}$ except in one study which showed a reduction of between $17 \%$ and $65 \%{ }^{22}$ Long-term improvements in lipid profiles were shown in the SOS study. Resolution of hypertriglyceridaemia (defined as level $<1.7 \mathrm{mmol} / \mathrm{L}$ ) was achieved by $62 \%$ of participants at two years and $46 \%$ at ten years. Resolution of low HDL-cholesterol (defined as level $\mathrm{HDL}>1.0 \mathrm{mmol} / \mathrm{L}$ ) was similar at two and ten years $\left(76 \%\right.$ and $73 \%$ respectively) after surgery. ${ }^{16}$

\section{BARIATRIC SURGERY AND QUALITY OF LIFE}

Several studies have reported that quality of life of patients improved after bariatric surgery. This includes improvement in general quality of life, weight related quality of life, physical activity, depression scores and self-esteem. ${ }^{29-32}$ Because of greater weight reduction after bariatric surgery, problems with excess skin could arise. This could lead to recurrent infections and discomfort. ${ }^{33}$ Unfortunately, body contouring surgery is not offered as part of the NHS service and patients should be warned of this possible adverse effect prior to bariatric surgery. 


\section{SAFETY OF BARIATRIC SURGERY}

With improved surgical technique, patient selection and preparation, bariatric procedures have mortality rates similar to common operations such as laparoscopic cholecystectomy, which has a mortality rate of up to $0.2 \% .{ }^{34}$ Although the gastric bypass appears to be more successful in diabetes remission, it is associated with a higher mortality and complication risk. The 30-day perioperative mortality rate for gastric bypass (up to $0.4 \%$ ) is at least four times higher when compared to the gastric band (up to $0.1 \%)^{7}$ At two years, the gastric band mortality rate $(0.0 \%)$ continues to be lower compared to the bypass $(0.4 \%) .{ }^{35}$ Recipients of the gastric bypass and sleeve are also at risk of nutritional deficiencies. ${ }^{36-39}$ The problems that might occur after the gastric band are usually due to mechanical failure of the band or lack of dietary adherence by patients, causing excessive vomiting, oesophageal dilatation, dysmotility and band slippage. $^{35}$ Operative technique has however been optimised to reduce risk of band slippage. ${ }^{40}$

\section{CONCLUSION AND UNRESOLVED QUESTIONS}

In obese diabetic patients, bariatric surgery results in significant weight reduction and great success in the remission in T2D mellitus in the short and medium-term. More data are still needed for assessing the long-term outcomes. The majority of bariatric procedures are carried out laparoscopically and the mortality and complications rates are usually very low. However, in those aged 60 years and above, perioperative risks and mortality rates appear to be higher. ${ }^{41,42} \mathrm{~A}$ thorough multidisciplinary assessment of patients is therefore important to weigh up risks and benefits prior to surgery.

Obesity and T2D are major challenges to the NHS. The choice of anti-obesity medication is limited and some anti-diabetes medications induce weight gain as an adverse effect. Compared to lifestyle interventions, glycaemic control, cardiometabolic risk and quality of life are more likely to be improved with bariatric surgery. Moreover, bariatric surgery has been shown to be costeffective. ${ }^{43}$ Ongoing and planned studies will ensure that better study designs are implemented which will strengthen the evidence-base for the use of bariatric surgery in cases of obesity complicated by T2D.

\section{REFERENCES}

I The NHS Information Centre. Health and lifestyles: summary of key findings [Internet].London:The Health and Social Care Information Centre; 2010 [cited 2012 June 14]. Available from: http://www. ic.nhs.uk/webfiles/publications/003_Health_Lifestyles/hse09report/ HSE_09_Summary.pdf

2 Wang YC, McPherson K, Marsh T et al. Health and economic burden of the projected obesity trends in the USA and the UK. Lancet 20II; 378:8I5-25. http://dx.doi.org/I0.10I6/SOI406736(II)608I4-3

3 Diabetes UK. Diabetes in the UK 201//20I2: key statistics on diabetes [Internet]. London: Diabetes UK; $201 \mathrm{I}$ [cited 2012 May 25]. Available from: http://www.diabetes.org.uk/documents/ reports/diabetes-in-the-uk-20I I-I2.pdt

4 Wing RR. Long-term effects of a lifestyle intervention on weight and cardiovascular risk factors in individuals with type 2 diabetes mellitus: four-year results of the Look AHEAD trial. Arch Int Med 2010; I70:1566-75. http://dx.doi.org/10.1001/archinternmed.2010.334

5 Dixon JB, O'Brien PE, Playfair J et al.Adjustable gastric banding and conventional therapy for type 2 diabetes: a randomized controlled trial.JAMA 2008;299:316-23.http://dx.doi.org/I0.100I/jama.299.3.316

6 Wadden TA, Volger S, Sarwer DB et al.A two-year randomized trial of obesity treatment in primary care practice. N Engl J Med 20I I; 365: I 969-79. http://dx.doi.org/ I0.1056/NEJMoal I09220

7 Flum DR, Belle SH, King WC et al. Perioperative safety in the longitudinal assessment of bariatric surgery. New Engl J Med 2009; 361:445-54. http://dx.doi.org// 0.1056/NEJMoa0901836

8 Dixon JB, Zimmet P, Alberti KG et al. Bariatric surgery: an IDF statement for obese type 2 diabetes. Surg Obes 2011; 7:433-47. http://dx.doi.org/l0.1016/j.soard.2011.05.013

9 National Institute for Health and Clinical Excellence. Obesity: the prevention, identification, assessment and management of overweight and obesity in adults and children [Internet]. London: NICE; 2006 [cited 2012 Jun 14]. Available from: http://www.nice.org.uk/ nicemedia/pdf/CG43NICEGuideline.pdf

10 Scottish Intercollegiate Guidelines Network. Management of obesity : a national clinical guideline [Internet]. Edinburgh:SIGN; 2010 [cited 2012 May 25]. Available from: http://www.sign.ac.uk/ guidelines/fulltext/I I5/index.html

I I DateY, Kojima M, Hosoda $\mathrm{H}$ et al. Ghrelin, a novel growth hormonereleasing acylated peptide, is synthesized in a distinct endocrine cell type in the gastrointestinal tracts of rats and humans. Endocrinology 2000; |41:4255-6I. http://dx.doi.org//0.1210/en. I4I.II.4255

12 De Silva A, Bloom SR. Gut hormones and appetite control: a focus on PYY and GLP-I as therapeutic targets in obesity. Gut Liver 2012; 6:10-20. http://dx.doi.org//0.5009/gnl.2012.6.1.10

13 Arita $\mathrm{Y}$, Kihara S, Ouchi $\mathrm{N}$ et al. Paradoxical decrease of an adipose-specific protein, adiponectin, in obesity. Biochem Biophys Res Comm 1999; 257:79-83. http://dx.doi.org//10.1006/bbrc.1999.0255

14 Weyer C, Funahashi T, Tanaka S et al. Hypoadiponectinemia in obesity and type 2 diabetes: close association with insulin resistance and hyperinsulinemia. J Clin Endocrinol Metab 200I; 86:1930-5. http://dx.doi.org//0.1210/jc.86.5.1930

15 Butner KL, Nickols-Richardson SM, Clark SF et al. A review of weight loss following Roux-en-Y gastric bypass vs restrictive bariatric surgery: impact on adiponectin and insulin. Obes Surg 2010; 20:559-68. http://dx.doi.org/I0.I007/s I I695-0I0-0089-z

16 Sjostrom L, Lindroos AK, Peltonen $M$ et al. Lifestyle, diabetes, and cardiovascular risk factors 10 years after bariatric surgery. $N$ Engl J Med 2004; 35l:2683-93. http://dx.doi.org/l0.1056/ NEJMoa035622

17 Barr EL, Zimmet PZ,Welborn TA et al. Risk of cardiovascular and allcause mortality in individuals with diabetes mellitus, impaired fasting glucose, and impaired glucose tolerance: the Australian Diabetes, Obesity, and Lifestyle Study (AusDiab). Circulation 2007; I16:15I-7. http://dx.doi.org/I0.I I6I/CIRCULATIONAHA.106.685628

18 Buse JB, Caprio S, Cefalu WT et al. How do we define cure of diabetes? Diabetes Care 2009; 32:2 I33-5. http://dx.doi.org//0.2337/ dc09-9036 
19 Buchwald H, Estok R, Fahrbach K et al.Weight and type 2 diabetes after bariatric surgery: systematic review and meta-analysis. Am J Med 2009; 122:248-56 e5.

20 Buchwald $\mathrm{H}$, Avidor $\mathrm{Y}$, Braunwald $\mathrm{E}$ et al. Bariatric surgery: a systematic review and meta-analysis. JAMA 2004; 292:1724-37. http://dx.doi.org//0.100I/jama.292.I4.1724

2I Dixon JB, Murphy DK, Segel JE et al. Impact of laparoscopic adjustable gastric banding on type 2 diabetes. Obes $\operatorname{Rev} 2012$; |3:57-67. http://dx.doi.org/I0.1 I I I/j. I467-789X.20 I I.00928.x

22 Mingrone G, Panunzi S, De Gaetano A et al. Bariatric surgery versus conventional medical therapy for type 2 diabetes. New Engl J Med 20 I2; 366: I 577-85. http://dx.doi.org/ I0.1056/NEJMoa I 200 I I I

23 Lee WJ, Chong K, Ser KH et al. Gastric bypass vs sleeve gastrectomy for type 2 diabetes mellitus: a randomized controlled trial. Arch Surg 20II; 146:I43-8. http://dx.doi.org/l0.100I/ archsurg.2010.326

24 Pournaras DJ,Aasheim ET, Sovik TT et al. Effect of the definition of type II diabetes remission in the evaluation of bariatric surgery for metabolic disorders. $\mathrm{Br} J$ Surg 2012; 99:100-3. http://dx.doi. org/l0.1002/bjs.7704

25 Heneghan HM, Meron-Eldar S, Brethauer SA et al. Effect of bariatric surgery on cardiovascular risk profile. Am J Cardiol 20I I; 108:1499-507.

26 Sarkhosh K, Birch DW, Shi $X$ et al. The impact of sleeve gastrectomy on hypertension: a systematic review. Obes Surg 2012; 22:832-7. http://dx.doi.org/I0.1007/s | I695-012-06/5-2

27 Dixon JB, O'Brien PE. Lipid profile in the severely obese: changes with weight loss after lap-band surgery. Obes Res 2002; 10:903-10. http://dx.doi.org// 0.1038/oby.2002.124

28 Zhang F, Strain GW, Lei W. Changes in lipid profiles in morbidly obese patients after laparoscopic sleeve gastrectomy (LSG). Obes Surg 20 I I; 2 I:305-9. http://dx.doi.org/ I0.1007/s I I695-0 I0-0285-x

29 Sovik TT, Aasheim ET, Taha $O$ et al.Weight loss, cardiovascular risk factors, and quality of life after gastric bypass and duodenal switch: a randomized trial. Ann Intern Med 20I I; I55:28I-9I.

30 O'Brien PE, Dixon JB, Laurie C et al. Treatment of mild to moderate obesity with laparoscopic adjustable gastric banding or an intensive medical program: a randomized trial. Ann Intern Med 2006; I44:625-33.

3I Dymek MP, Le Grange D, Neven K et al. Quality of life after gastric bypass surgery: a cross-sectional study. Obes Res 2002; 10: I I 35-42. http://dx.doi.org/10.1038/oby.2002.154

32 Boan J, Kolotkin RL,Westman EC et al. Binge eating, quality of life and physical activity improve after Roux-en-Y gastric bypass for morbid obesity. Obes Surg 2004; 14:34I-8. http://dx.doi. org/I0.138I/0960892043229|7864
33 Kitzinger HB, Abayev S, Pittermann A et al. After massive weight loss: patients' expectations of body contouring surgery. Obes Surg 2012; 22:544-8. http://dx.doi.org/ I0.1007/s I I695-0 I I-055 I-6

34 Steiner CA, Bass EB, Talamini MA et al. Surgical rates and operative mortality for open and laparoscopic cholecystectomy in Maryland. New Engl J Med 1994; 330:403-8. http://dx.doi.org/I0.1056/ NEJMI99402103300607

35 Buchwald $\mathrm{H}$, Estok R, Fahrbach $\mathrm{K}$ et al. Trends in mortality in bariatric surgery: a systematic review and meta-analysis. Surgery 2007; 142:62I-32; discussion 32-5. http://dx.doi.org//0.1016/j. surg.2007.07.018

36 Pajecki D, Dalcanalle L, Souza de Oliveira CP et al. Follow-up of Roux-en-Y gastric bypass patients at 5 or more years postoperatively. Obes Surg 2007; 17:60I-7. http://dx.doi. org/I0.1007/s I I695-007-9I04-4

37 Fujioka K, DiBaise JK, Martindale RG. Nutrition and metabolic complications after bariatric surgery and their treatment. JPEN J Parenter Enteral Nutr 20II; 35:52S-9S. http://dx.doi. org/I0. I I77/0 |48607 I I |4|3600

38 Saif T, Strain GW, Dakin G et al. Evaluation of nutrient status after laparoscopic sleeve gastrectomy I, 3, and 5 years after surgery. Surgery Obes Relat Dis. Epub 2012 Feb I. http://dx.doi.org/I0.1016/j. soard.2012.01.013

39 Damms-Machado A, Friedrich A, Kramer KM et al. Pre- and postoperative nutritional deficiencies in obese patients undergoing laparoscopic sleeve gastrectomy. Obes Surg 2012; 22:88I-9. http:// dx.doi.org/I0.I007/s I I695-0 I2-0609-0

40 Singhal R, Super P. Gastric banding - to band or bypass. The case for laparoscopic banding. Ann R Coll Surg Engl 2008; 90:4-6.

4l Wool D, Bellatorre N,Wren S et al. Male patients above age 60 have as good outcomes as male patients $50-59$ years old at I-year follow-up after bariatric surgery. Obes Surg 2009; 19:18-21. http:// dx.doi.org/ I0.1007/s I I695-008-9734-I

42 Sosa JL, Pombo H, Pallavicini $\mathrm{H}$ et al. Laparoscopic gastric bypass beyond age 60. Obes Surg 2004; 14:1398-40I. http://dx.doi. org/l 0.138 I/0960892042583833

43 Picot J, Jones J, Colquitt JL et al. The clinical effectiveness and costeffectiveness of bariatric (weight loss) surgery for obesity: a systematic review and economic evaluation. Health Technol Assess 2009; 13:1-190, 215-357, iii-iv.

\section{SENIOR FELLOWS' CLUB PRIZE}

A prize of $£ 250$ will be awarded to the first-named (or corresponding) author of an original research paper on a clinical topic, deemed by a panel of judges to be the best paper by a doctor-in-training (i.e. pre-consultant level) published in the The Journal of the Royal College of Physicians of Edinburgh in 2012. The best paper will be selected by a panel of judges, including a senior Fellow, an active clinician and a member of the editorial team.

Further details may be obtained from the Editorial Office, RCPE, 9 Queen Street, Edinburgh, EH2 IJQ, tel 0|3। 2473652 or email editorial@rcpe.ac.uk. 